\title{
Age and Gender Differences in the Self-Esteem of Chinese Children
}

\author{
DAVID WATKINS \\ Department of Education \\ University of Hong Kong \\ QI DONG \\ YONG XIA \\ Department of Education \\ Beijing Normal University
}

\begin{abstract}
A Chinese version of the Self-Description Questionnaire I (SDQ- I: Marsh. 1988) was used to investigate age and gender differences in a sample of 303 male and 296 female 10-year-old children and 116 male and 116 female 1,3-year-old children attending typical Beijing public schools. Significant Age $\times$ Gender interaction effects were found on all 8 SDQ-1 scales. Main effects for age were found on the Physical Abilities, Reading. and School subscales and for gender on the same three subscales plus Peer Relations. Further analysis indicated that the older girls tended to report significantly lower self-esteem than both the younger girls and older boys in the areas of physical abilities, reading. mathematics, and general self-concept. The boys reported more positive self-perceptions on most nonacademic self-scales, but both the older boys and older girls reported less favorable self-esteem than their younger peers on the scales for reading and school in general.
\end{abstract}

AFTER AN EXTENSIVE REVIEW of the research literature on relationships between self-esteem, age, and gender. Wylie (1979) concluded that there was no evidence of any consistent, significant relationships. However. she did point to the poor quality of the theorizing, measurement, and research methodology in the self-concept literature at that time, qualities that may have masked the extent of such relationships. A particular problem was the reliance on measures of overall self-esteem that were not particularly well constructed. Wylie pointed out that age and gender differences might have existed in specific facets of self-esteem, some favoring men and older respondents but other facets favoring women and younger respondents; when these elements were combined, however, there appeared to be no overall effects.

Address correspondence to David Watkins, Department of Edacation, University of Hong Kong, Pokfulam Road. Hong Kong. 
More recent reviews of the literature by Hattie (1992) and Marsh (1989) have indicated that Wylie's suspicions were correct. Hattie reported that a largescale study of Australian adolescents indicated that with increasing age, there were significant decreases in means for academic and family self-esteem but not for self-esteem related to peers, self-confidence, or the physical self. Hattie also reported on a meta-analysis based on over 600 studies of gender differences in self-concept. He concluded that there was little evidence for overall differences in self-esteem, but men did tend to give higher self-ratings in the areas of verbal competence and physical appearance. Marsh (1989), in reviewing data archives based on his Self-Description Questionnaire (SDQ; Marsh, 1988)-considered by Hattie (1992) to be the best of the existing self-esteem questionnaires and to possess impressive psychometric properties-concluded that self-esteem declined with age from early preadolescent years to middle adolescence, then leveled out, only to increase again in late adolescence and early adulthood. Marsh (1989) reached conclusions similar to Hattie's about gender differences in self-concept and pointed out that these were generally consistent with gender role stereotypes. The possibility of Age $\times$ Gender interaction effects on selfesteem has rarely been investigated. Marsh (1993) found no significant interaction effect, but Hattie (1992) concluded that, unlike their adolescent counterparts, women tend to report higher self-esteem than men.

One of the disappointing aspects of research in this area is that the aforementioned findings are based almost exclusively on studies carried out in Western countries, particularly in North America and Australia. Several major papers (Markus \& Kitayama, 1991; Triandis, 1989) have pointed out variations in the ways people from different cultures tend to think about themselves. People from Western cultures tend to have an individualistic self-concept, with the emphasis on individual characteristics and achievement, whereas those from non-Western cultures tend to report a collectivistic self-conception in which the person does not think about himself or herself so much as an individual but rather in terms of relations with other people (e.g., as a daughter, husband, Muslim). Western findings about age and gender effects on self-esteem consequently may not be generalizable to non-Western cultures.

However, it is also clear that many characteristics of age and gender have a universal, physiological basis. From about 8-9 years of age, all children throughout the world experience major changes that may well lead to changes in or threats to their self-concept (Hattie, 1992). At about that age, there is a marked increase in the growth of brain cells, particularly in the frontal lobes, that lead to the development of higher cognitive processes, such as planning and intentional and abstract behaviors (Luria, 1973), or to formal operational thought (in Piagetian terms). There are also universal physiological changes related to puberty that may affect boys' and girls' perceptions of the self. Related to these bodily changes is the almost universal transition from primary to secondary school at about 11 to 13 years of age. This transition is often associated with changes in 
the nature of instruction and different expectations on the part of teachers, family, and peers (Hattie, 1992). Thus, given the existence of relatively universal changes related to gender, age, and cultural differences in the nature of one's selfconcept, it is an open question whether Western findings on the effects of age and gender on self-concept will be replicated in non-Western cultures.

In the present study, therefore, we examined the self-esteem of children from the People's Republic of China. In Chinese society, there has traditionally been a bias in favor of male children, but observers have reported no evidence in the Chinese classroom of differential treatment favoring boys, which has so often been noted in U.S. classrooms. A study of 189 Chinese university students found no statistically significant gender differences in overall self-esteem; the women's self-ratings were higher in the academic area but lower than the men's regarding being cultured, having special talents, receiving personal recognition, meeting personal goals, and having spiritual beliefs (Watkins \& Yu, 1993).

\section{Method}

\section{Participants}

The sample consisted of 303 male and 296 female primary school students with an average age of 10.2 years (the younger group), and 116 male and 116 female secondary school students, with an average age of 13.1 years (the older group). All attended typical public schools in the same area of urban Beijing.

\section{Instrument}

The version of the SDQ for younger children, the Self-Description Questionnaire-1 (SDQ-1; Marsh, 1988), was used to assess self-esteem. It consists of 64 items designed to measure seven specific facets of self, based on Shavelson, Hubner, and Stanton's (1976) hierarchical model of self-concept and a general self-scale derived from the Rosenberg (1979) Self-Esteem Scale (see Marsh, 1988, for further details and for evidence of the reliability and validity of the SDQ-1 scales for Australian students). The seven specific facets measured by the eight-item subscales are physical abilities/sports (Phys). physical appearance (Appr), peer relations (Peer), parent relations (Prnt), reading (Read), mathematics (Math), and general school (Schl). Respondents answer each item on a 5-point scale ranging from false (1), to sometimes false/sometimes true (3), to true (5).

Subscales $1-4$ and 5-7 can be summed to obtain nonacademic and academic self-scores, respectively. All 64 items can also be summed to obtain a total selfesteem score (TOTAL).

A Chinese version of the SDQ- 1 was developed with the traditional backtranslation method. The scales of the Chinese SDQ-1 have very adequate internal consistency and reliability (alpha) estimates, ranging from .77 to .90 and .78 
to .89 for the younger and older samples, respectively. The Chinese SDQ- 1 has an underlying factor model, as predicted by theory, and correlates as predicted with teacher estimates of students' self-esteem (Watkins \& Dong, 1994; Watkins, Dong, \& Xia, 1995).

\section{Results}

Interaction effects significant at the .01 level were found for all 8 SDQ-1 subscales (see Table 1 for means of the SDQ- 1 scales obtained for the younger and the older students, by gender, and Table 2 for the Age $\times$ Gender analyses of variance testing the statistical significance of differences between these means). Statistically significant main effects for age were found on the Physical Abilities, Reading, and School subscales (where the interaction effects were particularly strong) and for gender on these same three scales plus the Peer Relations subscale.

Because of the presence of such strong interaction effects, we conducted further univariate tests, to try to sort out the relationships (see Table 1). There was an overall trend for the older girls to report markedly statistically significant lower self-esteem than both their younger female counterparts and the older boys in the areas of physical abilities, reading, mathematics, and general self-concept. Although the boys showed significantly more positive self-perceptions in most nonacademic areas, both the older boys and girls tended to rate themselves less favorably than their younger peers regarding reading and school in general.

TABLE 1

Means of SDQ-1 Scales by Age Group and Gender, and Absolute Differences in Means of SDQ-1 Scales Between Older and Younger Participants

\begin{tabular}{|c|c|c|c|c|c|c|}
\hline \multirow[b]{3}{*}{ SDQ-1 subscales } & \multicolumn{2}{|c|}{ Younger } & \multicolumn{2}{|c|}{ Older } & \multirow{2}{*}{\multicolumn{2}{|c|}{ Older-Younger }} \\
\hline & \multirow{2}{*}{$\begin{array}{c}\text { Boys } \\
(n=303)\end{array}$} & \multirow{2}{*}{$\begin{array}{c}\text { Girls } \\
(n=296)\end{array}$} & \multirow{2}{*}{$\begin{array}{c}\text { Boys } \\
(n=116)\end{array}$} & \multirow{2}{*}{$\begin{array}{c}\text { Girls } \\
(n=116)\end{array}$} & & \\
\hline & & & & & Boys & Girls \\
\hline Physical Abilities & 29.48 & $28.16^{\mathrm{a}}$ & 29.09 & $25.41^{\mathrm{b}}$ & -0.39 & $-2.75^{d}$ \\
\hline Physical Appearance & 27.72 & $29.29^{\mathrm{a}}$ & 29.48 & 29.54 & $+1.76^{\mathrm{c}}$ & +0.25 \\
\hline Peer Relations & 28.43 & $30.32^{\mathrm{a}}$ & 29.50 & 29.41 & $+1.07^{\mathrm{c}}$ & $-0.91^{d}$ \\
\hline Parental Relations & 32.90 & $34.06^{\mathrm{a}}$ & 34.29 & 34.50 & $+1.39^{\mathrm{c}}$ & +0.44 \\
\hline Reading & 30.27 & $33.06^{\mathrm{a}}$ & 28.44 & $30.01^{\mathrm{b}}$ & $-1.83^{c}$ & $-3.05^{\mathrm{d}}$ \\
\hline Mathematics & 31.63 & 31.68 & 31.19 & $29.84^{\mathrm{b}}$ & -0.44 & $-1.84^{\mathrm{d}}$ \\
\hline General School & 29.18 & $31.46^{\mathrm{a}}$ & 27.87 & 27.96 & $-1.31^{\mathrm{c}}$ & $-3.50^{d}$ \\
\hline General Self & 28.71 & $29.75^{a}$ & 29.12 & $27.92^{\mathrm{b}}$ & +0.41 & $-1.83^{\mathrm{d}}$ \\
\hline
\end{tabular}

Note. Significant differences at the .01 level: "between gender means for younger participants; between gender means for older participants; cbetween older-younger means for boys; dbetween older-younger means for girls. 
TABLE 2

Summary $F$ Statistics of Age $\times$ Gender

Analysis of Variance of SDQ-1 Scales

\begin{tabular}{lrrc}
\hline \hline SDQ-1 subscales & Age & Gender & Age $\times$ Gender \\
\hline Physical Abilities & 9.23 & $18.17^{*}$ & $32.43^{*}$ \\
Physical Appearance & 3.73 & 5.99 & $11.74^{*}$ \\
Peer Relations & 0.03 & $8.57^{*}$ & $12.38^{*}$ \\
Parental Relations & 3.90 & 4.39 & $9.19^{*}$ \\
Reading & $24.00^{*}$ & $30.16^{*}$ & $55.97^{*}$ \\
Mathematics & 4.61 & 0.53 & $6.86^{*}$ \\
General School & 24.92 & $14.87^{*}$ & $45.22^{*}$ \\
General Self & 2.64 & 1.12 & $10.44^{*}$ \\
\hline
\end{tabular}

$" p<.01$.

\section{Discussion}

Measurement of self-esteem has improved markedly in recent years, and future researchers can now focus on issues of major theoretical and practical interest, such as how self-esteem develops and how it can be changed (Hattie, 1992). A mapping of age and gender differences should provide a basis for understanding such issues. Such data are needed from different cultures, to eliminate confounding of universal and culturally specific trends.

The results of this study suggest that as Chinese children progress through high school, their academic self-esteem drops. However, the self-esteem of the older girls drops lower than that of their male peers and of the younger girls. Boys show more positive self-perceptions in nonacademic areas than girls do.

We can only speculate on the causes of these trends in terms of, perhaps, the effect of earlier puberty on girls' self-esteem and growing awareness of biases against girls in Chinese society. However, the magnitude of the age by gender effects found in this study of typical Beijing adolescents indicates that important changes in self-regard among Chinese girls and women may now be occurring. The results of Watkins and Yu's (1993) study suggest that these effects may have less impact on women who have proved their worth by winning a place at a prestigious university. We suggest that there is a need for longitudinal studies to confirm our findings and to probe the possible causes.

This study also confirms the need to use a multifaceted self-concept instrument, such as the SDQ-1, in future research in this area. Moreover, further qualitative work, with a free-response instrument such as the Twenty Statements Test (Kuhn \& McPartland, 1954), is needed to explore the possibility that (as Josephs, Markus, and Tafarodi, 1992, argued for Western cultures) the self-concepts of Chinese men and women may differ. 


\section{REFERENCES}

Hattie, J. (1992). Self-concept. Hillsdale, NJ: Erlbaum.

Josephs, R. A., Markus, H. R., \& Tafarodi, R. W. (1992). Gender and self-esteem. Journal of Personality and Social Psychology, 63, 391-402.

Kuhn, M. H., \& McPartland, T. (1954). An empirical investigation of self-attitudes. American Sociological Review, 19, 68-76.

Markus, H., \& Kitayama, S. (1991). Culture and the self: Implications for cognition, emotion, and motivation. Psychological Review, 98, 224-253.

Marsh, H. (1988). The Self-Description Questionnaire I: SDQ manual and research monograph. San Antonio, TX: The Psychological Corporation.

Marsh, H. (1989). Age and sex effects in multidimensional self-concept: Pre-adolescence to early adulthood. Journal of Educational Psychology, 8I, 417-430.

Marsh, H. W. (1993). The multidimensional structure of academic self-concept: Invariance over gender and age. American Educational Research Journal, 30, 841-860.

Rosenberg, M. (1979). Conceiving the self. New York: Basic Books.

Shavelson, R. J., Hubner, J. J., \& Stanton, G. C. (1976). Self-concept: Validation of construct interpretations. Review of Educational Research, 46, 407-441.

Triandis, H. C. (1989). The self and social behavior in differing cultural contexts. Psychological Review, 96, 506-520.

Watkins, D., \& Dong, Q. (1994). Assessing the self-esteem of Chinese school children. Educational Psychology, 14, 129-137.

Watkins, D., Dong, Q., \& Xia, Y. (1995). Towards the validation of a Chinese version of the Self-Description Questionnaire 1. Psychologia, 38, 22-30.

Watkins, D., \& Yu, J. (1993). Gender differences in the source and level of self-esteem of Chinese college students. The Journal of Social Psychology, 133, 347-352.

Wylie, R. C. (1979). The self-concept. Lincoln: University of Nebraska Press.

Received January 23, 1996 